\title{
BELEROFONTINAS (MOLLUSCA: GASTROPODA?) \\ DEVONIANOS DO ESTADO DO PARANÁ (FORMAÇÃO \\ PONTA GROSSA, BACIA DO PARANÁ): GÊNERO \\ BUCANELLA MEEK, 1871
}

\author{
Angela Marchioro, Carla Bender Kotzian e Raquel Ilha Simões \\ Departamento de Biologia - CCNE \\ UFSM, Santa Maria, RS
}

RESUMO

Neste estudo, a ocorrência das espécies do gênero Bucanella Meek, 1871, em estratos devonianos do Estado do Paraná é revisada. Redescrições são apresentadas para as quatro espécies estudadas: Bucanella laticarinata Knod, 1908, Bucanella dereimsi Knod, 1908, Bucanella hapsideus (Clarke, 1913) e Bucanella quadrilobata (Salter, 1856). Para as duas últimas são propostas novas combinações. $\boldsymbol{B}$. quadrilobata é registrada pela primeira vez na Formação Ponta Grossa. O status de Plectonotus e Bucanella é discutido. Considerações sobre as afinidades das taxocenoses de gastrópodes da Formação Ponta Grossa são apresentadas.

\section{ABSTRACT}

In this study, previous records of the genus Bucanella Meek, 1871 species in Devonian beds from Paraná State are revised. Redescriptions are presented to the four species studied: Bucanella 
laticarinata Knod, 1908, Bucanella dereimsi Knod, 1908, Bucanella hapsideus (Clarke, 1913) and Bucanella quadrilobata (Salter, 1856). To the last two, new combinations are proposed. $\boldsymbol{B}$. quadrilobata is recorded for the first time in the Ponta Grossa Formation. The status of Plectonotus and Bucanella is discussed. Considerations about the affinities of gastropod taxocoenoses from the Ponta Grossa Formation are presented.

\section{1 - INTRODUÇÃO}

O primeiro estudo a tratar da identidade e da morfologia dos gastrópodes da Formação Ponta Grossa (Bacia do Paraná) no Estado do Paraná é o trabalho de CLARKE (1913). Nesta obra, que pode ser considerada o marco referencial pioneiro e um clássico sobre a fauna devoniana das camadas em apreço, o autor registra a ocorrência de "Pleurotomaria kayseri Ulrich; Plectonotus (Bucaniella) dereimsi Knod", descreve a espécie nova Ptomatis moreirai e um gastrópode que denomina Bellerophon sp.

KOTZIAN \& MARCHIORO (1991) comentam que, em coleções paleontológicas nacionais, existem certos exemplares muito diferentes daqueles já descritos, que podem constituir espécies novas. Mencionam, também que alguns desses espécimes possuem características não citadas nas descrições ou redescrições de espécies já conhecidas, enquanto outros representam formas já descritas, mas não assinaladas na Formação Ponta Grossa.

KOTZIAN \& MARCHIORO (1997) revisam parte do material supracitado e descrevem uma espécie nova, Ptomatis paranaensis; redescrevem Ptomatis moreirai Clarke, 1913, Platyceras (Platyostoma) allardycei (Clarke, 1913); discutem a inclusão de $P$. (?) kayseri no gênero Pleurotomaria e registram pela primeira vez a presença de $\boldsymbol{P}$. (P.) allardycei e de um espécime pateliforme nos estratos devonianos do Paraná. Comentam, ainda, que o gênero Ptomatis e o exemplar pateliforme 
podem representar monoplacóforos, mas que uma posição conclusiva não pode ser tomada, pois dependeria da observação de caracteres não preservados no material examinado, como as impressões musculares.

O presente estudo tem como objetivo principal dar continuidade à pesquisa de KOTZIAN \& MARCHIORO (1997), revisando as espécies restantes, isto é, os gastrópodes ou monoplacóforos do gênero Bucanella. Como a posição estratigráfica de alguns afloramentos dos quais procedem os moluscos em questão é conhecida, esta pesquisa procura, também, determinar a distribuição cronoestratigráfica das espécies estudadas. Além disso, apresenta algumas considerações finais onde é discutida a afinidade das taxocenoses dos gastrópodes da Formação Ponta Grossa com a de faunas de estratos devonianos de outras regiões.

\section{2 - GENERALIDADES SOBRE A FORMAÇÃO PONTA GROSSA}

O intervalo representado pelo Siluro-Devoniano, e talvez pelo Ordoviciano, corresponde à primeira fase de subsidência da bacia. Todos os clásticos que atualmente preenchem essa "Primeira Bacia do Paraná" foram depositados durante dois grandes ciclos transgressivo-regressivos do mar paleozóico de então (ZALÁN et alii, 1990; ASSINE et alii, 1994). A Formação Ponta Grossa, gerada numa fase transgressiva, assenta-se sobre a Formação Furnas, sendo ambas consideradas de idade devoniana (fig. 1).

Segundo RAMOS (1970), a Bacia do Paraná apresentava-se tectonicamente compartimentada no Devoniano. Dados estratigráficos de superfície e subsuperfície indicariam que naquele período a Bacia possuía dois depocentros: um ao sul e outro ao norte. As áreas a eles correspondentes são então consideradas, pelo referido autor, como duas sub-bacias designadas, respectivamente, de Apucarana e Alto Garças (fig. 2). Ambas estariam parcialmente separadas pelos altos de Três Lagoas e Campo Grande, mas conectadas pelo Sinclinal do Alto Araguaia. A sub-bacia de Apucarana ocuparia áreas hoje correspondentes aos estados de São 
Paulo, Paraná e Santa Catarina. A sub-bacia de Alto Garças ocuparia grande parte dos estados de Mato Grosso, Mato Grosso do Sul e do sudoeste de Goiás.

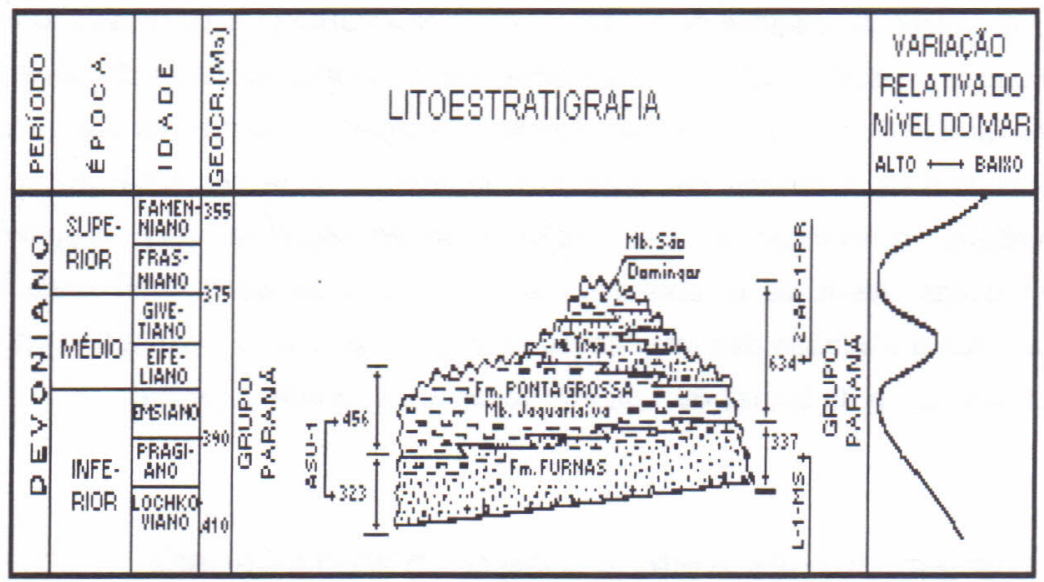

Figura 1 - Coluna estratigráfica da seqüência devoniana da Bacia do Paraná (modificada de ASSINE et alii, 1994.)

A natureza do contato das formações Furnas e Ponta Grossa é muito discutida. Para alguns autores (e. g. LANGE \& PETRI, 1967; ASSINE \& SOARES, 1989; ASSINE et alii, 1994) é concordante; para outros, discordante (ZALÁN et alii, 1987, 1990).

Já o contato superior com os sedimentos neocarboníferos é, claramente, uma discordância, abrangendo um período de tempo em torno de 60 a 70 M. a. (ZALÁN et alii, 1987).

A Formação Ponta Grossa foi subdividida por LANGE \& PETRI (1967) em membros inferior, médio e superior, denominados, respectivamente, como Jaguariaíva, Tibagi e São Domingos. O Membro Jaguariaíva é composto, predominantemente, por folhelhos argilosos a sílticos e, subordinadamente, por arenitos finos; o Membro Tibagi é formado por arenito fino, micáceo e síltico, e o Membro São Domingos compreende 
folhelhos cinzentos a pretos, algo betuminosos, arenitos finos e conglomerados. Segundo os autores supracitados, esta divisão é melhor observada no Estado do Paraná.

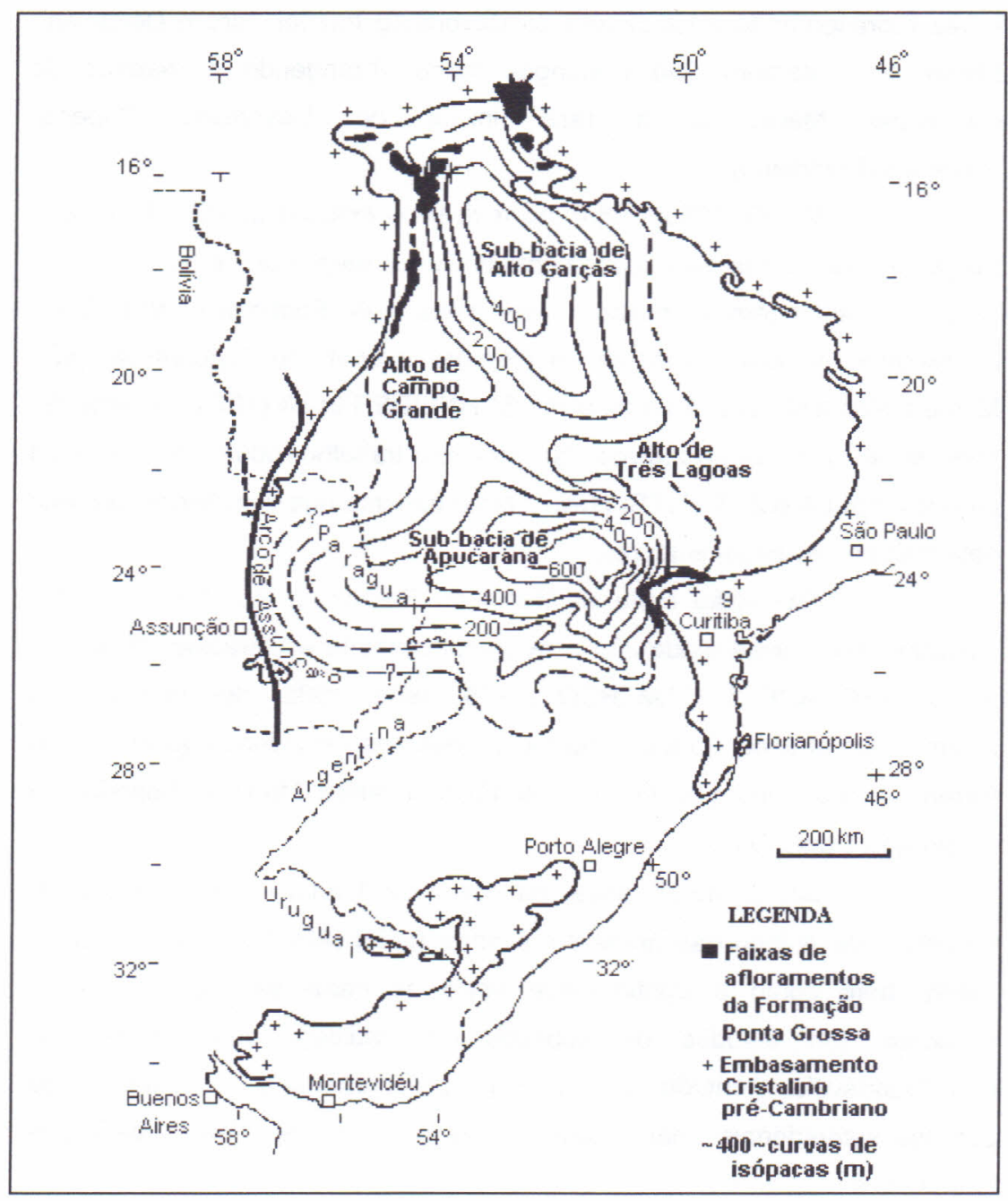

Figura 2 - Mapa de isópacas da Formação Ponta Grossa, mostrando as faixas de afloramentos e os depocentos das sub-bacias de Alto Garças e Apucarana (modificado de J.L. Pantoja, apud ZALÁN et alii, 1990) 
DAEMON et alii (1967) e LANGE (1967), com base em estudos sobre quitinozoários, acritarcos e esporos propuseram a seguinte datação para cada membro: o Membro Jaguariaíva é considerado como Devoniano Inferior (Emsiano); o Membro Tibagi, como Devoniano Médio (Eifeliano), talvez representando a passagem do Devoniano Inferior para o Devoniano Médio, e o Membro São Domingos como abrangendo o restante do Devoniano Médio e a fase inicial do Devoniano Superior (Givetiano/Frasniano).

MELO (1985, 1988), ao revisar os estudos sobre a Formação Ponta Grossa, propôs alterações nomenclaturais para a unidade. Com base na prioridade de termos, passou a denominá-la de Formação Santa Rosa, modificando, também, o nome do Membro Inferior, ou Jaguariaíva, para Membro Ponta Grossa. Autores como SCHNEIDER et alii (1974), no entanto, consideram a formação indivisa. No presente trabalho, adotou-se a divisão proposta por LANGE \& PETRI (1967), procedimento que vem sendo utilizado pela maioria dos pesquisadores.

$\mathrm{Na}$ região norte da Bacia do Paraná, a litoestratigrafia das camadas devonianas ainda não está completamente esclarecida. No sul de Goiás, ANDRADE \& CAMARÇO $(1978,1980,1982)$ denominaram os sedimentitos lá encontrados, contemporâneos aos devonianos do Estado do Paraná, como Formação Furnas, membros Inferior, Médio e Superior da "Formação Ponta Grossa".

MELO (1985) observou que a similaridade entre o conteúdo fossilifero devoniano das áreas sul e norte (RONCARATI, 1968; GLASER, 1969), bem como a continuidade entre as camadas destas regiões, verificada em estudos de subsuperfície, indicam que ambas são correlacionáveis. Contudo, o caráter predominantemente arenoso dos estratos setentrionais não permite designá-los de Formação Ponta Grossa s. s.

Os afloramentos da Formação Ponta Grossa ocorrem de forma muito localizada. No Estado do Paraná, são encontrados próximo ao bordo leste da Bacia, ao redor do Arco de Ponta Grossa (fig. 2). Na área norte da 148 Rev. Ciência e Natura. Santa Maria, 20: 143 - 185 , 1998 
Bacia, os sedimentitos mostram-se à superfície nos Estados de Mato Grosso e Mato Grosso do Sul acompanhando o flanco noroeste e, em Goiás, ao longo do flanco nordeste (fig. 2).

O conteúdo fossilífero da unidade em apreço é constituído por diversos grupos de invertebrados (e.g. conulárias, gastrópodes, bivalves, tentaculitóides, trilobitas e braquiópodes) que confirmam o caráter marinho de seus sedimentitos. A identidade dessa associação de invertebrados é extremamente semelhante àquela verificada em outras áreas devonianas brasileiras e em áreas contemporâneas da Bolívia, Argentina, Ilhas Malvinas e África do Sul (Cidade do Cabo) (CLARKE, 1913). A similaridade da fauna dessas áreas e a dessemelhança da mesma em relação a associações homócronas boreais, encontradas ao norte do Equador, fez com que a região por ela ocupada passasse a ser designada de Província Malvinocáfrica (RICHTER \& RICHTER, 1942; BOUCOT, 1971, 1985).

\section{3 - MATERIAL E MÉTODOS}

\section{1) Material Examinado}

Foram examinados cerca de 40 exemplares, depositados nas seguintes instituições: Seção de Paleontologia do Departamento Nacional de Produção Mineral (DNPM/DGM-I), no Rio de Janeiro; Museu de História Natural Capão da Imbuia (MHNCl) e Museu de Paleontologia da Universidade Federal do Paraná (MP-UFPR), ambos em Curitiba; Museu da Casa de Cultura de Ponta Grossa (MCCPG), em Ponta Grossa e Museu de Paleontologia da Universidade Federal do Rio Grande do Sul (MP-UFRGS), em Porto Alegre. Com exceção dos espécimes do DNPM, os demais pertencem a coleções didáticas. Aqueles doados para esse estudo têm como repositório a Coleção Científica do Departamento de Paleontologia e Estratigrafia do Instituto de Geociências da Universidade de São Paulo (USP-GPE), onde também se encontra o material coletado, pessoalmente, pelos autores. Os exemplares estudados por CLARKE (1913), que 
descreveu várias espécies encontradas no Devoniano paranaense, estão depositados no DNPM. As coleções e instituições mencionadas acima passarão a ser referidas, ao longo do texto, por suas respectivas siglas.

\section{2) Procedência do Material Examinado}

Os espécimes utilizados no presente estudo são provenientes de afloramentos localizados no flanco leste da Bacia, isto é, no Estado do Paraná, mais precisamente nos municípios de Jaguariaíva, Ponta Grossa e Palmeira (fig. 3).

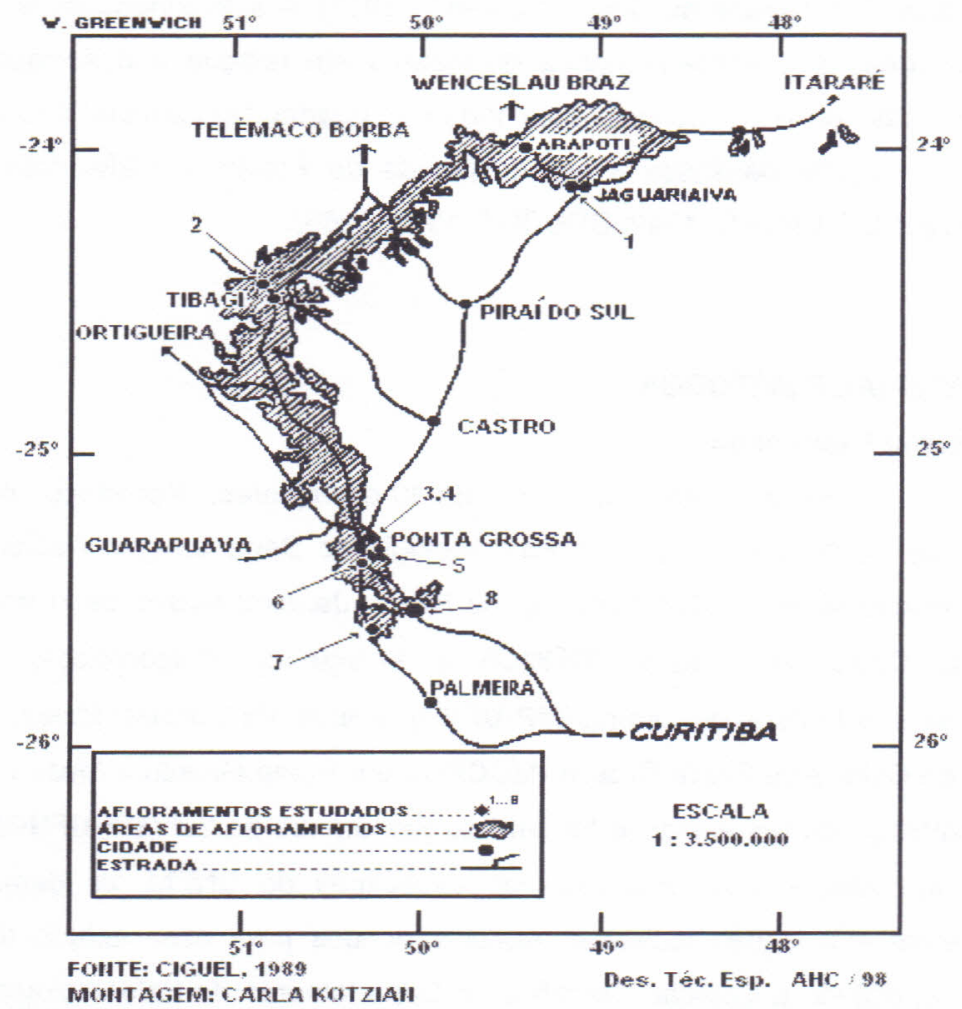

Figura 3 - Mapa de localização de alguns afloramentos devonianos do Estado do Paraná (modificado de CIGUEL, 1989). 1 - Jaguariaíva, 2 - Tibagi, 3 Metalúrgica Águia, 4 - Curva I, 5- Vila Placidina, 6- Vendrami, 7- Rio Caniú, 8- Vila Velha 
Os livros de registro das instituições visitadas nem sempre indicam o nome do afloramento, no qual os exemplares, neles registrados, foram coletados. Ainda assim, foi possível listar o jazigo de origem de alguns espécimes (Quadro 1).

\begin{tabular}{|l|c|l|c|}
\hline \multicolumn{1}{|c|}{ AFLORAMENTO } & ABREVIATURA & LOCALIDADE & ABREVIATURA \\
\hline Curva I ${ }^{*}$ & $\mathrm{Cl}$ & Ponta Grossa & PG \\
\hline Vila Velha & VV & Ponta Grossa & PG \\
\hline Vila Placidina (= Posto) & VP & Ponta Grossa & PG \\
\hline Vendrami & VD & Ponta Grossa & PG \\
\hline Metalúrgica Águia & MA & Ponta Grossa & PG \\
\hline Rio Caniú & CN & Palmeira & PL \\
\hline $\begin{array}{l}\text { Corte na Estrada de } \\
\text { Ferro Jaguariaiva-Arapoti }\end{array}$ & CE & Jaguariaíva & JG \\
\hline
\end{tabular}

Quadro 1 - Nomes e abreviaturas dos afloramentos estudados e suas respectivas localidades.

* Esse afloramento também é chamado Localidade A25 (LANGE, 1967) e Bairro Baraúna (BOSETTI, 1989; CIGUEL, 1989).

Dos afloramentos registrados no Quadro 1, três são datados através de microfósseis ou atribuídos a algum membro da Formação Ponta Grossa, tal como especificado abaixo.

- Corte na Estrada de Ferro: Devoniano Inferior/Membro Jaguariaíva (LANGE, 1967; LANGE \& PETRI, 1967)

- Curva I: base do Membro São Domingos (POPP, 1985; POPP \& BARCELLOS-POPP, 1986). Obs. MELO (1988) propõe idade mais antiga, provavelmente Membro Jaguariaíva/Emsiano (com. pessoal).

- Rio Caniú: topo do Membro São Domingos (POPP, 1985; POPP \& BARCELLOS-POPP, 1986) 


\section{3) Limpeza e Fotografia}

Quando necessário, os exemplares para estudo foram preparados de forma usual: utilizaram-se estiletes, martelos e brocas de tipos variados. As dimensões dos exemplares quebrados ou muito deformados não foram tomadas. Aqueles ligeiramente deformados apresentam suas medidas acompanhadas por um asterisco $\left(^{*}\right)$ no item "Dimensões".

Os espécimes que ilustram este trabalho foram fotografados em aparelho REPROVIT, com filme preto e branco ORWO. As estampas foram reproduzidas em Copiadora Xerox modelo 5765.

\section{4) Procedimentos Sistemáticos}

A sistemática utilizada, a nível supragenérico, é aquela proposta no Treatise on Invertebrate Paleontology (KNIGHT et alii, 1960). Subgêneros e espécies são discutidos utilizando-se bibliografia especializada.

estado de fossilização do material examinado, que poderia interferir na determinação e descrição das espécies estudadas, é comentado nos itens "Material Examinado" e "Observações".

O estado de preservação dos exemplares nem sempre permite uma clara observação de determinadas características e/ou dimensões, utilizando-se, então, nas redescrições, termos como "aparentemente" ou "provavelmente", comentados posteriormente em "Observações".

Com a intenção de agilizar e facilitar a consulta ao item "Material Examinado", as informações sobre os espécimes estão organizadas sob a forma de tabela, onde constam: a) número do exemplar; b) modo de fossilização (fos): molde interno (MI), molde composto (MC), contramolde (CM); c) posição do plano sagital em relação ao plano de acamamento (pos): paralela $(=)$, perpendicular (I), inclinada (/), desconhecida (?); d) grau de compactação (com.): alto (+), moderado $( \pm)$, 
não compactado (-); e) afloramento de origem (afl.) e f) localidade (município) de origem (pro.).

As listas sinonímicas das espécies incluem apenas artigos que apresentam descrições e/ou ilustrações dos exemplares. Trabalhos contendo somente citações de espécies, bem como check lists, não são mencionados.

Para as espécies descritas por CLARKE (1913), sem designação original de holótipos, foram determinados lectótipos, selecionados entre os síntipos depositados no DNPM. Para as demais espécies, holótipos e lectótipos não são aqui registrados, posto que os síntipos, coletados em território sul-africano, não foram por nós examinados.

Os termos utilizados para orientar e descrever as espécies do gênero Bucanella são aqueles propostos por MOORE (1960); (fig. 4). As expressões "volta geradora" e "taxa de expansão" são empregadas segundo as definições de RAUP \& STANLEY (1971).

A orientação do eixo anteroposterior dos belerofontáceos ainda é assunto de discussão (PEEL, 1987; RUNNEGAR, 1987). Por essa razão, no presente estudo, as regiões anterior e posterior de Bucanella foram determinadas arbitrariamente, de modo a facilitar a caracterização morfológica das espécies.

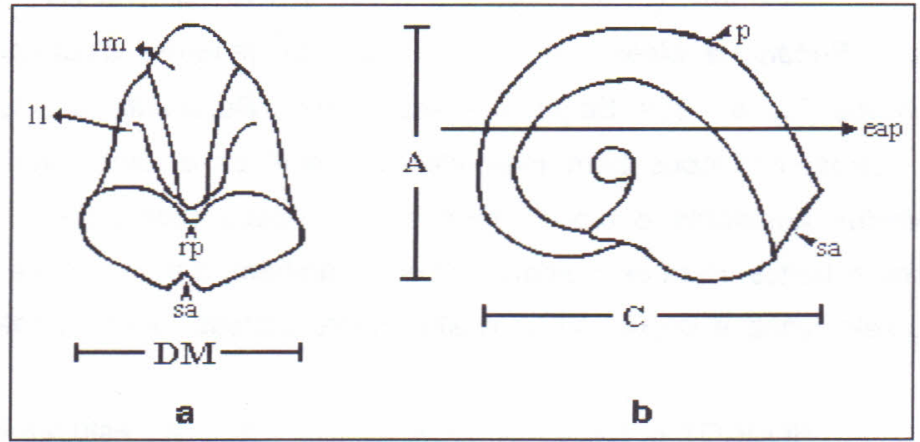

Fig. 4 - Termos descritivos e orientação utilizados para caracterizar as espécies estudadas. Fig. a) Vista posteroventral. Legenda: DM - diâmetro máximo; II lobo lateral; Im - lobo médio; rp - ranhura posterior; sa - sinus anterior. Fig. b) Vista lateral. Legenda: A - altura; C - comprimento; eap - eixo anteroposterior; $\mathrm{p}$ - periferia; sa - sinus anterior. 


\title{
4. SISTEMÁTICA
}

\author{
Filo Mollusca \\ Classe Gastropoda Cuvier, 1797 \\ Subclasse Prosobranchia Milne Edwards, 1848 \\ Ordem Archaeogastropoda Thiele, 1925 \\ Subordem Bellerophontina Ulrich \& Scofield, 1827 \\ Superfamília Bellerophontacea M'Coy, 1851 \\ Família Sinuitidae Dall in Zittel-Eastman, 1913 \\ Subfamília Bucanellinae Koken, 1925 \\ Gênero: Bucanella Meek, 1871 \\ Espécie-tipo: Bucanella nana Meek, 1871 \\ (por designação original)
}

\section{Diagnose:}

Concha trilobada; lobo mediano mais proeminente que os lobos laterais; sem selenizona; com pseudo-selenizona.

\section{Discussão:}

Conforme a classificação proposta por KNIGHT et alii (1960), o gênero Bucanella Meek, 1871 inclui dois subgêneros: Bucanella e Plectonotus Clarke, 1899. Segundo esses autores, Bucanella caracterizase por apresentar lobos bem marcados e umbílicos amplos, enquanto Plectonotus apresenta o lobo central amplo, pouco pronunciado e os umbílicos estreitos. Para este último atribuem, também, a presença de uma pseudo-selenizona e de um sinus relativamente estreito, com formato de "V".

BOUCOT \& SAUL (in SAUL et alii, 1963), ao estudarem os fósseis devonianos de Ghana (África), elaboraram uma revisão para o taxon Plectonotus, elevando-o à categoria de gênero. A razão para esta modificação de categoria taxonômica seria a presença de selenizona em 154 Rev. Ciência e Natura, Santa Maria. 20: 143 - 185 , 1998 
P. derbyi (Clarke, 1899), a espécie-tipo de Plectonotus. Embora os referidos autores não tenham examinado o holótipo de $\boldsymbol{P}$. derbyi, a existência desta estrutura na espécie-tipo, segundo eles, teria sido claramente enfatizada na discussão apresentada por CLARKE (1899):

"Bucanella deve ser restrito ao grupo trilobatus de costas largas trilobadas e sem cinta. Para as espécies trilobadas e com cinta sou obrigado a introduzir um nome novo, Plectonotus, visto ser certamente de considerável significação taxonômica a presença ou ausência desta feição".

A posição dos referidos autores é reiterada por BOUCOT et alii (1986), onde os mesmos também propõem a inclusão de dois subgêneros no gênero em apreço: Plectonotus e Plectonotoides, diferenciados entre si pelo menor tamanho do último.

Pelo que se pode depreender do trabalho original de CLARKE (1899), o termo cinta refere-se a uma região deprimida do lobo mediano e não a uma selenizona sensu strictu (KNIGHT et alii, 1960, p. I119). Ou seja, a mesma não é formada por uma série de lúnulas crescentes, em uma região escavada. Embora a ilustração de CLARKE (1899, Est. III, figs. 14 a 18) para Plectonotus derbyi não deixe claro a ausência ou presença de selenizona, as fotos do holótipo, apresentadas por KNIGHT (1941, PI. 7, figs. $4 a, 4 b)$ demonstram, claramente, apenas a existência de uma região mais deprimida, ou seja, de uma pseudo-selenizona como consta na diagnose de Plectonotus apresentada por KNIGHT et alii (1960). Provavelmente, por este motivo, os autores supracitados utilizaram o termo pseudo-selenizona, e não selenizona, na diagnose de Plectonotus.

HARRISON \& HARRISON (1970), através de informações fornecidas por Yochelson, consideraram que o holótipo de $\boldsymbol{P}$. derbyi não apresenta selenizona. Por este motivo, ambos também mantém Plectonotus como subgênero de Bucanella.

KOTZIAN \& MARCHIORO (1991), ao estudarem os gastrópodes do Devoniano paranaense depositados no DNPM, registraram espécimes coletados por M. Roxo, no Estado do Pará. Entre eles, 
observaram representantes de $\boldsymbol{B}$. ( $\boldsymbol{P}$.) derbyi, que exibem, nitidamente, a marca de uma selenizona s. s. (Est. II, fig. 2).

Uma vez confirmada a presença da estrutura supracitada em $\boldsymbol{P}$. derbyi e tendo em vista seu elevado valor taxonômico (ver discussão apresentada adiante no item 5), os autores do presente trabalho corroboram a proposta de BOUCOT \& SAUL (in SAUL et alii, 1963) e mantêm Plectonotus na categoria de gênero. O gênero Bucanella, conseqüentemente, ficaria restrito às formas similares sem selenizona, mas com pseudo-selenizona.

Já a proposta de criar dois subgêneros - Plectonotus e Plectonotoides - apresentada por BOUCOT et alii (1986) é bastante questionável. A diferença de tamanho não parece constituir um bom caráter taxonômico; o "nanismo" de Plectonotoides poderia estar associado a fatores ambientais ou evolutivos (GOULD, 1977; SEILACHER, 1984).

Diversos espécimes de Bucanella aqui estudados permitem definir a pseudo-selenizona como uma região achatada ou ligeiramente convexa na periferia da concha, mal delimitada do restante do lobo médio e melhor definida pela sinuosidade da ornamentação comarginal.

As espécies aqui estudadas exibem certas feições que poderiam ser usadas para propor-se subgêneros para Bucanella: os umbílicos, apesar do tamanho variável, são sempre pequenos se comparados ao da espécie-tipo desse gênero, B. nana; o formato do sinus anterior pode apresentar configuração em "V" ou "U" e a região posterior pode apresentar ranhura ou não. Entretanto, para que uma proposição conclusiva fosse aqui assumida, seria necessário observar um número de espécies bem maior do que aquele ora analisado, para se verificar até que ponto tais caracteres ou suas combinações são mutuamente excludentes. Esse tipo de estudo - uma revisão genérica - foge ao escopo do presente trabalho, e por essa razão o gênero Bucanella é aqui tratado sem a preocupação em se definir subgêneros. 
1908 - Bucaniella laticarinata: KNOD, p. 505, Taf. XXII, figs. 6, 6a.

1913 - Bucaniella laticarinata Knod: KOZLOWSKI, p. 114, PI. II, figs. 12, $12 \mathrm{a}$.

1965 - Bucanella (Plectonotus) laticarinata: BRANISA, Est. 27, fig. 16.

1966 - Bucaniella laticarinata Knod: CASTELLARO, p. 115.

1970 - Bucanella (Plectonotus) sp.: HARRISON \& HARRISON, p. 217, PI. 3, figs. 10,11 e 12 .

\section{Diagnose:}

Volta corporal acentuadamente convexa; lobo mediano com largura aproximadamente três vezes maior do que a largura dos lobos laterais; lobos laterais pouco convexos; pseudo-selenizona localizada na periferia do lobo mediano; região mediana posterior com uma ranhura estreita; linhas de crescimento finas e concêntricas; sinus estreito e longo, com formato de "V"; umbílicos pequenos.

\section{Redescrição:}

Concha planoespiralada, algo comprimida lateralmente, involuta, isostrófica, trilobada. Alcança $29 \mathrm{~mm}$ de comprimento, $24 \mathrm{~mm}$ de altura e $21 \mathrm{~mm}$ de diâmetro máximo. Número de voltas desconhecido, devido à involução da concha. Volta corporal trilobada, acentuadamente convexa. Lobo mediano convexo, amplo, com largura, aproximadamente, três vezes maior que a largura dos lobos laterais. Apresenta, em sua periferia, uma região achatada e estreita que confere à concha um aspecto quadrilobado. Lobos laterais pouco convexos, separados do lobo mediano por um sulco raso e ligeiramente marcado. Região posterior com uma ranhura estreita na porção mediana. Ornamentação constituída por linhas de crescimento finas e concêntricas, bem próximas umas das outras, 
apresentando inflexão angulosa, bastante acentuada na região dorsomediana, que acompanha o contorno do sinus anterior. Abertura nitidamente trilobada, apresentando sinus estreito, longo e com formato de "V" na periferia do lobo mediano; região mediana-posterior com uma sinuosidade, decorrente da ranhura posterior. Pseudo-selenizona caracterizada pela inflexão das linhas concêntricas. Concha biumbilicada. Umbílicos pequenos.

\section{Material Examinado:}

\begin{tabular}{|c|c|c|c|c|c|}
\hline №. do exemplar & Fos. & Com. & Pos. & Afl. & Pro. \\
\hline GPE-1T 1889 & $\mathrm{MC}$ & + & $=$ & MA & $P G$ \\
\hline GPE-1T 1890 & $\mathrm{MC}$ & (6) & 1 & MA & $P G$ \\
\hline GPE-1T 1891 & $\mathrm{Ml}$ & (6) & $=$ & $\mathrm{CN}$ & $\mathrm{PL}$ \\
\hline GPE-1T 1892 & $\mathrm{MC}$ & (6) & $?$ & $\mathrm{CN}$ & $\mathrm{PL}$ \\
\hline GPE-1T 1893 & $\mathrm{MC}$ & - & $?$ & $\mathrm{CN}$ & $\mathrm{PL}$ \\
\hline GPE-1T 1894 & $\mathrm{Ml}$ & (6) & $?$ & VV & $P G$ \\
\hline GPE-1T 1895 & $\mathrm{MI}$ & - & 1 & VV & $P G$ \\
\hline GPE-1T 1896 & $\mathrm{Ml}$ & (6) & $=$ & VV & $P G$ \\
\hline
\end{tabular}

\section{Distribuição geográfica:}

Estados Unidos: Ohio (HARRISON \& HARRISON, 1970); Bolívia: Icla e Padilla (KNOD, 1908 e BRANISA, 1965); Argentina: San Juan (CASTELLARO, 1966); Brasil: Estado do Paraná (KOZLOWSKI, 1913), Palmeira e Ponta Grossa.

\section{Distribuição estratigráfica:}

Estados Unidos: Siluriano Superior (HARRISON \& HARRISON, 1970); Bolívia: Devoniano Inferior (KNOD, 1908; BRANISA, 1965); Argentina: Devoniano Inferior (CASTELLARO, 1966); Brasil: Formação Ponta Grossa, Devoniano (KOZLOWSKI, 1913), Membro São Domingos. 
Dimensões (em milímetros):

\begin{tabular}{|c|c|c|c|}
\hline $\begin{array}{l}\text { № } \\
\text { EXEMPLAR }\end{array}$ & DO & C & DM \\
\hline GPE-1T 1889 & 24 & 29 & - \\
\hline GPE-1T 1890 & - & 27 & - \\
\hline GPE-1T 1891 & 16 & 19 & 11 \\
\hline GPE-1T 1892 & 17 & 22 & 14 \\
\hline GPE-1T 1893 & 18 & 23 & 21 \\
\hline GPE-1T 1895 & - & 18 & 15 \\
\hline GPE-1T 1896 & 11 & 15 & - \\
\hline
\end{tabular}

\section{Observações:}

Nos exemplares estudados, foi observada a presença de uma ranhura ou sulco que acompanha a região mediana posterior da concha e que se reflete na sua margem posterior (Est. I, fig. 1a). Esta característica, até o momento, não havia sido mencionada nas descrições anteriores da espécie (KNOD, 1908; KOZLOWSKI, 1913; CASTELLARO, 1966). Talvez, as condições de fossilização dos exemplares estudados naqueles trabalhos, não tenham permitido a visualização desta característica. Nos próprios exemplares aqui examinados, esta feição só é observada em exemplares pouco deformados e com a região mediana posterior visível. A região deprimida, evidenciada na periferia do lobo mediano (Est. I, figs. 2a, 2b), não parece deixar vestígios de uma selenizona verdadeira, podendo ser considerada como uma pseudo-selenizona.

\section{Discussão:}

As características gerais dos lobos da concha, o tipo de ornamentação e a presença de um sinus longo e estreito, com formato de "V" (Est. I, figs. 1b, 2b), permitem atribuir os exemplares estudados à espécie Bucanella laticarinata Knod, 1908. Os exemplares apresentam, contudo, a ranhura posterior mencionada anteriormente, que até o momento não havia sido registrada.

Os exemplares de B. laticarinata, aqui estudados, mostram ligeiras diferenças, em relação àqueles atribuídos por outros autores a esta 
mesma espécie. Estas diferenças, muito pequenas, são aqui consideradas como variações intra-específicas. A descrição e a ilustração apresentadas por KOZLOWSKI (1913, pl. II, figs. 12, 12a) para um exemplar paranaense, por exemplo, demonstram que este possui maior convexidade em todos os lobos, quando comparado aos espécimes ora estudados. A presença de sinus não foi descrita, nem pode ser observada nas referidas ilustrações. Contudo, os umbílicos do gastrópode por ele ilustrado são estreitos e a largura dos lobos apresenta-se tal como nos espécimes aqui analisados. 0 exemplar encontrado na Argentina, atribuído à espécie B. laticarinata Knod, 1908 por CASTELLARO (1966), difere dos exemplares examinados por apresentar lobo mediano mais anguloso e umbílicos elípticos. Porém, a periferia do lobo mediano ligeiramente achatada indica que o mesmo pertence a B. laticarinata. O exemplar registrado por BRANISA (1965, lám. 27, fig. 16) para a Bolívia, denominado como B. laticarinata, foi apenas figurado. A ilustração, apesar de não ser muito nítida, indica que o mesmo parece pertencer a um exemplar da espécie em questão, devido à involução da concha, aos umbílicos estreitos, ao lobo mediano proeminente e delimitado por sulcos bem marcados e por parecer apresentar sinus em forma de "V". A espécie registrada por HARRISON \& HARRISON (1970), para os Estados Unidos, denominada Bucanella (Plectonotus) sp., é provavelmente atribuível à $\boldsymbol{B}$. laticarinata. O exemplar apresenta abertura nitidamente trilobada, lobos mediano e laterais pouco convexos e sinus longo.

Os exemplares aqui estudados permitem observar que $\boldsymbol{B}$. laticarinata apresenta afinidades com duas espécies do Devoniano paranaense (CLARKE, 1913): Bucanella hapsideus Clarke, 1913 e Bucanella dereimsi Knod, 1908. A primeira apresenta, em comum, a trilobação da concha, a periferia do lobo mediano achatada e as linhas de crescimento comarginais. Porém, seus umbílicos são mais circulares, os lobos laterais e medianos mais convexos e o sinus anterior tem formato de "U" (Est. II, fig. 7). B. dereimsi difere de B. laticarinata, principalmente, pela 
presença de estrias radiais na superfície dos lobos mediano e laterais e pela maior taxa de expansão da volta corporal (Est. I. figs. 3, 4, 5, 6).

Os espécimes aqui examinados demonstram também, que $\boldsymbol{B}$. laticarinata apresenta semelhanças com algumas espécies sul-africanas estudadas por REED (1904). Bellerophon (Bucanella) aff. trilobatus Sowerby, 1904 conforme a descrição do autor supracitado, é similar à espécie paranaense pela involução da concha, proeminência subangular do lobo mediano e lábio externo emarginado na região posterior. No entanto, difere por apresentar umbílicos bem mais estreitos e profundos, lobos laterais e mediano mais convexos e abertura mais expandida. Bellerophon (Bucanella) cf. reissi Clarke, 1899 assemelha-se aos espécimes aqui estudados pelo arredondamento geral do lobo mediano, taxa de expansão baixa e umbílicos estreitos e profundos. Porém, difere pela trilobação pouco nítida, pelo contorno mais fraco da abertura e pelos lobos laterais deprimidos.

Bucanella quemadensis Feruglio, 1930, descrita e ilustrada por CASTELLARO (1966) para Argentina, assemelha-se no aspecto geral a B. laticarinata. Difere, no entanto, em algumas características. Os umbílicos são maiores e circulares e os sulcos laterais são muito profundos. Além disto, o lobo mediano é menos anguloso e proeminente, correspondendo apenas a $1 / 3$ do diâmetro da volta corporal.

A espécie Kokenospira trimetra, descrita e ilustrada por ÖPIK (1953) para Austrália (Vitória), se parece com B. laticarinata pela trilobação nítida e pelo umbílico ligeiramente amplo. No entanto, difere por apresentar lobo mediano mais convexo e saliente, pela acentuada depressão que separa os lobos laterais do lobo mediano e pelo sinus posterior raso.

Bucanella dereimsi Knod, 1908

(Est. I, figs. 3, 4a, 4b, 5, 6)

1904 - Bellerophon (Bucaniella) aff. trilobatus, Sowerby: REED, p. 242; PI. XXX; fig. 5. 
1908 - Bucaniella dereimsi: KNOD, p. 506, Taf. XXII, figs. 4, 4a, 5.

1913 - Plectonotus (Bucaniella) dereimsi Knod: CLARKE, p. 165, Est. IX, figs. $13,14,15,16$ e 17.

1925 - Bellerophon (Plectonotus) cf. dereimsi (Knod): REED, p. 113.

\section{Diagnose:}

Volta corporal moderadamente convexa, fortemente expandida; lobos mediano e laterais aproximadamente com a mesma largura; lobos laterais acentuadamente convexos, mais salientes no adulto; linhas de crescimento finas e comarginais, estrias radiais mais pronunciadas nos lobos laterais; abertura expandida transversalmente; sinus profundo e em forma de "U"; umbílicos pequenos, elípticos e profundos.

\section{Redescrição:}

Concha planoespiralada, involuta, isostrófica, nitidamente trilobada. Alcança aproximadamente $17 \mathrm{~mm}$ de altura, $18 \mathrm{~mm}$ de comprimento e $44 \mathrm{~mm}$ de diâmetro máximo. Número de voltas desconhecido devido à involução da concha. Volta corporal moderadamente convexa e fortemente expandida lateralmente. Lobos mediano e laterais aproximadamente com a mesma largura, mais pronunciados à medida que a concha aumenta de tamanho. Lobos laterais acentuadamente convexos, separados do lobo mediano por um sulco profundo. Ornamentação constituída por linhas de crescimento finas e comarginais e por estrias radiais, que nos indivíduos jovens são mais pronunciadas nos lobos laterais. Abertura trilobada e expandida transversalmente. Sinus profundo, em forma de "U". Pseudo-selenizona pouco marcada, concha biumbilicada. Umbílicos muito pequenos e profundos. Ranhura posterior não observada. 
Material Examinado:

\begin{tabular}{|c|c|c|c|c|c|}
\hline № . do exemplar & Fos. & Com. & Pos. & Afl. & Pro. \\
\hline DGM-I $1562^{a}$ & $\mathrm{MI}$ & + & 1 & $?$ & $P G$ \\
\hline DGM-I 98 & $\mathrm{MC}$ & + & 1 & $?$ & $P G$ \\
\hline DGM-I 99 & MC? & + & 1 & $?$ & $P G$ \\
\hline DGM-I 100 & $\mathrm{MC}$ & + & 1 & $?$ & $P G$ \\
\hline DGM-I 101 & MC & + & 1 & $?$ & $P G$ \\
\hline GPE-1T 1897 & $\mathrm{MC}$ & + & $=$ & $\mathrm{CN}$ & $\mathrm{PL}$ \\
\hline GPE- 1T 1898 & $\mathrm{MC}$ & \pm & $=$ & $\mathrm{CN}$ & $\mathrm{PL}$ \\
\hline GPE- 1T 1899 & $\mathrm{MC}$ & \pm & $=$ & $\mathrm{CN}$ & $\mathrm{PL}$ \\
\hline GPE- 1T 1900a & $\mathrm{MC}$ & \pm & $=$ & $\mathrm{CN}$ & $P L$ \\
\hline GPE-1T 1900b & $\mathrm{MC}$ & \pm & $=$ & $\mathrm{CN}$ & $P L$ \\
\hline GPE-1T 1901 & $\mathrm{MC}$ & + & $=$ & $\mathrm{CN}$ & $\mathrm{PL}$ \\
\hline
\end{tabular}

\section{Distribuição geográfica:}

África do Sul: Gydo Pass e Camadas Bokkeveld (REED, 1904, 1925); Bolívia: Tacopaya e Icla (KNOD, 1908); Brasil: Estado do Paraná, Ponta Grossa e Tibagi (CLARKE, 1913); Jaguariaíva (POPP \& BARCELLOS-POPP, 1986), Palmeira.

\section{Distribuição estratigráfica:}

África do Sul: Devoniano, Camadas Bokkeveld (REED, 1904, 1925); Bolívia: Devoniano (KNOD, 1908); Brasil: Formação Ponta Grossa, Devoniano (CLARKE, 1913); Devoniano Inferior (POPP \& BARCELLOSPOPP, 1986); Membro São Domingos (Devoniano Médio/Superior).

Dimensões (em milímetros):

\begin{tabular}{|c|c|c|c|}
\hline $\begin{array}{ll}\begin{array}{l}\text { №. } \\
\text { EXEMPLAR }\end{array} & \text { DO } \\
\end{array}$ & A & C & DM \\
\hline DGM-I 1562 & - & - & 26 \\
\hline DGM-I 98 & - & 20 & 44 \\
\hline DGM-I 99 & - & - & 33 \\
\hline DGM-I 100 & - & - & 40 \\
\hline DGM-I 101 & - & 20 & 35 \\
\hline GPE-1T 1897 & 17 & 18 & - \\
\hline GPE-1T 1898 & 16 & $21^{*}$ & - \\
\hline GPE-1T 1899 & $14^{*}$ & $16^{*}$ & 11 \\
\hline GPE-1T $1900^{a}$ & 8 & 10 & - \\
\hline GPE-1T 1900b & 7 & 7 & - \\
\hline
\end{tabular}




\section{Observações:}

Pode-se observar, no material estudado, que há variação no pronunciamento das estrias radiais, conforme o estágio de desenvolvimento ontogenético de cada exemplar. Nas formas juvenis, as estrias são mais pronunciadas nos lobos laterais (Est. I, figs. 4a, 4b). Nos adultos, as estrias tornam-se mais evidentes no lobo mediano e mais finas nos lobos laterais. A volta corporal das formas adultas apresenta ornamentação concêntrica bem pronunciada.

Apesar dos exemplares examinados apresentarem-se compactados, é possível verificar que os lobos laterais e o mediano têm a mesma largura e que a abertura é lateralmente expandida (Est. I, figs. 3, 5, 6), sendo bem mais ampla que nas demais espécies de Bucanella, estudadas neste trabalho. Cabe salientar, ainda, a confirmação da observação de KNOD (1908) de que a espécie em questão é muito variável morfologicamente.

\section{Discussão:}

Os espécimes estudados pertencem à espécie Bucanella dereimsi Knod, 1908, já assinalada por CLARKE (1913) para o Estado do Paraná. Estes espécimes apresentam características típicas de $\boldsymbol{B}$. dereimsi, tais como lobos mediano e laterais aproximadamente com a mesma largura, estrias radiais em todos os lobos e abertura nitidamente trilobada e expandida transversalmente.

B. dereimsi apresenta semelhanças com Bucanella hapsideus (Clarke, 1913), discutida a seguir, que também ocorre no Estado do Paraná (CLARKE, 1913). Ambas assemelham-se pela trilobação geral da concha, forma do sinus posterior e pelas linhas de crescimento finas e comarginais. Porém, em $\boldsymbol{B}$. hapsideus não ocorrem estrias radiais nos lobos laterais e a abertura e a volta corporal são pouco expandidas (Est. II, figs. 6,7$)$. 
O gênero Bellerophon Montfort, 1808 é caracterizado por exibir voltas sem trilobação e selenizona bem marcada (KNIGHT, 1960). A nítida trilobação e especialmente a ausência de selenizona $s$. $s$. indicam que a espécie estudada não pode ser classificada entre os Bellerophon, tal como propõem alguns autores (vide sinonímia). A mesma deve ser mantida no gênero Bucanella, procedimento adotado por KNOD (1908), pois apresenta características diagnósticas desse taxon, entre elas, pseudoselenizona.

Bucanella hapsideus (Clarke, 1913) comb. nov.

(Est. II, figs. 1, 3, 4, 5, 6, 7, 8)

Lectótipo: DGM-I 104

Paralectótipos: DGM-I 102, 103 e 105.

Localidade-tipo: Ponta Grossa, Paraná.

Estrato-tipo: Formação Ponta Grossa.

1913 - Plectonotus (Bucaniella) hapsideus: CLARKE, p. 116, Est. IX, figs 1-5 1934 - Plectonotus (Bucaniella) hapsideus Clarke: MENDEZ-ALZOLA, p. 39. 1938 - Plectonotus (Bucaniella) hapsideus Clarke: MENDEZ-ALZOLA, p. 46, Lám. XI, fig. 6.

\section{Diagnose:}

Volta corporal muito convexa; lobo mediano proeminente, amplo, pouco convexo; periferia com uma região achatada, lembrando uma pseudo-selenizona; lobos laterais fortemente convexos; ornamentação constituída por linhas comarginais finas; estrias radiais presentes, apenas, no dorso do lobo mediano; abertura pouco expandida; sinus longo e estreito, em forma de "U"; umbílicos muito pequenos. 


\section{Redescrição:}

Concha planoespiralada, involuta, isostrófica, trilobada. Alcança $28 \mathrm{~mm}$ de comprimento, $24 \mathrm{~mm}$ de altura e $29 \mathrm{~mm}$ de diâmetro máximo. Número de voltas desconhecido devido à involução da concha. Volta corporal, aparentemente, muito convexa e trilobada. Lobo mediano proeminente, amplo, pouco convexo, apresentando uma região aparentemente achatada na periferia. Lobos laterais fortemente convexos, separados do lobo mediano por sulcos profundos. Lobo mediano e laterais aproximadamente com a mesma largura. Ornamentação constituída por linhas de crescimento comarginais. Estrias radiais nítidas sobre a periferia do lobo mediano e na região que delimita a pseudo-selenizona, pouco pronunciadas quando próximas dos sulcos. Abertura trilobada e pouco expandida. Sinus longo e estreito, em forma de "U". Pseudo-selenizona delimitada por ornamentação radial. Concha biumbilicada. Umbílicos muito pequenos. Ranhura posterior não observada.

Material Examinado:

\begin{tabular}{|c|c|c|c|c|c|}
\hline №. do exemplar & Fos. & Com. & Pos. & Afl. & Pro. \\
\hline DGM-I 102 & $M C$ & - & $=$ & ? & PG \\
\hline DGM-I 103 & $\mathrm{MC}$ & + & $=$ & $?$ & $P G$ \\
\hline DGM-I 104 & $\mathrm{MC}$ & - & 1 & $?$ & $\mathrm{PG}$ \\
\hline DGM-I 105 & $\mathrm{MC}$ & \pm & $=$ & $?$ & $P G$ \\
\hline DGM-I 362 & $\mathrm{MC}$ & + & 1 & $?$ & $?$ \\
\hline DGM-I 1562b & $\mathrm{MC}$ & - & $?$ & $?$ & $P G$ \\
\hline DGM-I 1562C & $\mathrm{MC}$ & - & $?$ & $?$ & $P G$ \\
\hline DGM-I $1977^{\mathrm{a}}$ & $\mathrm{Ml}$ & \pm & T & $\mathrm{CN}$ & $\mathrm{PL}$ \\
\hline DGM-I 1977b & $\mathrm{ME}$ & \pm & I & $\mathrm{CN}$ & $\mathrm{PL}$ \\
\hline DGM-I 1977c & $\mathrm{Ml}$ & \pm & $T$ & $\mathrm{CN}$ & $\mathrm{PL}$ \\
\hline DGM-I 1977d & $\mathrm{Ml}$ & \pm & 1 & $\mathrm{CN}$ & $\mathrm{PL}$ \\
\hline DGM-I 1977e & MI & \pm & $\mathrm{T}$ & $\mathrm{CN}$ & $\overline{\mathrm{PL}}$ \\
\hline DGM-I $1977 f$ & Ml & \pm & 1 & $\mathrm{CN}$ & PL \\
\hline DGM-I $1977 \mathrm{~g}$ & $\mathrm{MC}$ & \pm & $=$ & $\mathrm{CN}$ & $\mathrm{PL}$ \\
\hline GPE-1T 1902 & MC & 6 & 1 & $\mathrm{CN}$ & $\mathrm{PL}$ \\
\hline GPE-1T 1903 & $\mathrm{Ml}$ & + & $=$ & VD & $P G$ \\
\hline GPE-1T 1904 & $\mathrm{MC}$ & + & $=$ & VD & $P G$ \\
\hline GPE-1T 1905A/B & $\mathrm{MC}$ & + & $=$ & VD & $P G$ \\
\hline GPE-1T 1906 & $\mathrm{MC}$ & + & 1 & VD & $P G$ \\
\hline GPE-1T 1907 & $\mathrm{MC}$ & + & $=$ & VP & $P G$ \\
\hline
\end{tabular}




\section{Distribuição geográfica:}

Brasil: Estado do Paraná, Ponta Grossa (CLARKE, 1913), Palmeira; Uruguai: Rincón de Alonso, Arroyo del Cordobés e La Paloma (MENDEZ-ALZOLA, 1934, 1938).

\section{Distribuição estratigráfica:}

Brasil: Devoniano (CLARKE, 1913), Formação Ponta Grossa: Membro São Domingos; Uruguai: Devoniano (MENDEZ-ALZOLA, 1934, 1938).

Dimensões (em milímetros):

\begin{tabular}{lccc}
\hline №. DO EXEMPLAR & A & C & DM \\
\hline DGM-I 362 & 13 & - & 12 \\
DGM-I 102 & 11 & 11 & - \\
DGM-I 103 & 19 & 19 & - \\
DGM-I 104 & 16 & 17 & 12 \\
DGM-I 105 & 21 & 21 & - \\
DGM-I 1562b & - & 9 & - \\
DGM-I 1562c & - & 9 & - \\
DGM-I 1977a & 12 & 15 & $7^{\star}$ \\
DGM-I 1977b & 13 & 15 & $11^{\star}$ \\
DGM-I 1977c & - & - & $12^{\star}$ \\
DGM-I 1977d & 12 & 13 & - \\
DGM-I 1977e & 14 & - & - \\
DGM-I 1977f & 7 & 12 & 8 \\
DGM-I 1977g & 16 & 20 & - \\
GPE-1T 1902 & - & $26^{*}$ & 29 \\
GPE-1T 1903 & 24 & $28^{*}$ & - \\
GPE-1T 1904 & 18 & 26 & - \\
GPE-1T 1905A/B & 23 & $27^{\star}$ & - \\
GPE-1T 1906 & - & $24^{\star}$ & $17^{\star}$ \\
GPE-1T 1907 & $20^{\star}$ & $25^{\star}$ & - \\
\hline
\end{tabular}

\section{Observações:}

Quatro exemplares originalmente estudados por CLARKE (1913) estão depositados no DNPM e recebem numeração DGM-I 102, 103, 
104 e 105. Eles correspondem às figuras 5, 1, 3 e 4 da Estampa IX (CLARKE, 1913), respectivamente. O espécime DGM-I 104 é aqui escolhido como lectótipo e os demais, como paralectótipos.

Os exemplares estudados possibilitaram observar a existência de estrias radiais sobre o lobo mediano (Est. II, figs. 3, 7), as quais não haviam sido mencionadas na descrição original de $\boldsymbol{B}$. hapsideus (CLARKE, 1913). Constata-se, também, que a espécie apresenta sinus com formato de "U" (Est. II, figs. 3, 7), embora em exemplares fossilizados com o plano sagital paralelo ao substrato, o sinus pareça possuir formato de "V" (Est. II, figs. $4,5,8$ ). A pseudo-selenizona apresenta convexidade variável, podendo ser achatada (Est. II, fig. 4) ou regularmente convexa (Est. II, figs. 3, 7). No último caso, é inclusive, dificilmente delimitada do restante do lobo mediano. As condições de fossilização não permitem uma clara visualização da abertura. Supõe-se, no entanto, pelo que pode ser verificado em espécimes não deformados, que a mesma apresenta contorno trilobado, não expandindo lateralmente, acompanhando o formato da volta corporal.

\section{Discussão:}

O material examinado é atribuído à espécie Bucanella hapsideus (Clarke, 1913), já assinalada por CLARKE (1913) para o Estado do Paraná. Tal como esta espécie, os exemplares estudados apresentam linhas de crescimento comarginais, convexidade e largura dos lobos iguais e sinus estreito e longo. Cabe ressaltar, no entanto, que os espécimes aqui classificados como B. hapsideus possuem estrias radiais sobre o dorso do lobo mediano que não foram observadas nos exemplares originalmente estudados por CLARKE (1913). A não observação dessa feição pelo referido autor deve-se, provavelmente, ao fato de os gastrópodes por ele analisados estarem fossilizados com o plano sagital paralelo ao substrato (Est. II, figs. $1,4,5,8)$.

A espécie que mais se assemelha a $\boldsymbol{B}$. hapsideus é $\boldsymbol{B}$. dereimsi Knod, 1908. A semelhança entre ambas espécies foi comentada, 
anteriormente, na Discussão de $\boldsymbol{B}$. dereimsi. B. hapsideus também é muito semelhante a uma outra espécie estudada neste trabalho: $\boldsymbol{B}$. laticarinata Knod, 1908. Ambas apresentam trilobação nítida e linhas de crescimento finas e comarginais. No entanto, B. laticarinata apresenta ranhura medianaposterior, umbílicos maiores, lobo mediano angular sem estrias radiais e lobos mediano e laterais menos convexos.

Duas outras espécies são similares a $B$. hapsideus: Plectonotus derbyi Clarke, 1899 e B. quemadensis Feruglio, 1930. P. derbyi, descrita e ilustrada por CLARKE (1899) para o Devoniano do Estado do Pará, se parece com B. hapsideus pelo contorno da trilobação e pelo lobo mediano amplo, pronunciado e convexo. Porém, difere por apresentar sinus com formato de "V", selenizona verdadeira, linhas de crescimento excessivamente finas e pela ausência de estrias radiais. B. quemadensis, descrita e figurada por CASTELLARO (1966) para Argentina, parece com os exemplares paranaensis de $\boldsymbol{B}$. hapsideus pelo achatamento dorsal do lobo mediano e pela nítida trilobação. No entanto, a espécie argentina possui concha com volta corporal mais expandida e umbílicos maiores.

Por não possuir selenizona s. s. - característica diagnóstica do gênero Plectonotus - B. hapsideus é aqui removida deste taxon. A presença de pseudo-selenizona permite propor-lhe uma combinação nova: Bucanella hapsideus.

Bucanella quadrilobata (Salter, 1856) comb. nov. (Est. II, figs. 9a, 9b)

1856 - Bellerophon quadrilobatus: SALTER, p. 214, figs. 1, 2 1904 - Bellerophon quadrilobatus Salter: REED, p. 242.

1913 - Bellerophon quadrilobatus Salter ?: CLARKE, Est. IX, fig. 11. 1925 - Bellerophon (Plectonotus) quadrilobatus Salter: REED, p. 114. 1966 - Bellerophon quadrilobatus Salter ?: CASTELLARO, p. 118. 


\section{Diagnose:}

Volta corporal moderadamente expandida; lobo mediano pouco saliente, com largura aproximadamente três vezes maior do que a largura dos lobos laterais; lobos mediano e laterais regularmente convexos; linhas de crescimento não observadas; abertura ligeiramente trilobada, pouco expandida; sinus pouco profundo, em forma de "U"; umbílicos muito pequenos.

\section{Redescrição:}

Concha planoespiralada, involuta, isostrófica, trilobada. Alcança $17 \mathrm{~mm}$ de comprimento, $14 \mathrm{~mm}$ de altura e $16 \mathrm{~mm}$ de diâmetro máximo. Número de voltas desconhecido devido ao grau de involução da concha. Volta corporal moderadamente expandida. Lobo mediano convexo, pouco saliente, amplo, aproximadamente três vezes mais largo que os lobos laterais. Lobos laterais moderadamente arredondados, separados do lobo mediano por sulcos rasos. Ornamentação não observada. Abertura ligeiramente trilobada, pouco expandida. Sinus em forma de "U", pouco profundo. Pseudo-selenizona não observada. Concha biumbilicada. Umbílicos muito pequenos. Ranhura posterior não observada.

\section{Material Examinado:}

\begin{tabular}{|l|c|c|c|c|c|}
\hline № . do exemplar & Fos. & Com & Pos. & Afl. & Pro. \\
\hline DGM-I 1759 & MI & \pm & $/$ & CE & JG \\
\hline GPE-1T 1908 & CM & - & $?$ & Cl & PG \\
\hline
\end{tabular}

\section{Distribuição geográfica:}

África do Sul: Gydo Pass e Gamka Poort (REED, 1925); Argentina: Ilhas Malvinas (CLARKE, 1913; CASTELLARO, 1966); Brasil: Estado do Paraná, Ponta Grossa e Jaguariaíva. 


\section{Distribuição estratigráfica:}

África do Sul: Devoniano Inferior (REED, 1925); Argentina: Devoniano Inferior (CLARKE, 1913; CASTELLARO, 1966); Brasil: Paraná; Formação Ponta Grossa, Membro Jaguariaíva (Devoniano Inferior) e Membro São Domingos (Devoniano Médio/Superior).

Dimensões (em milímetros):

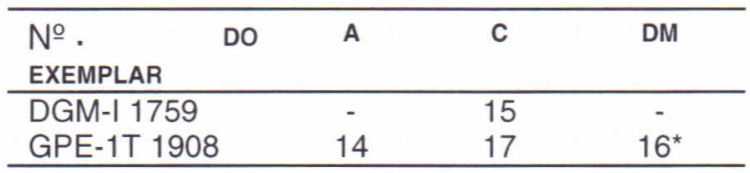

\section{Observações:}

Não foi possível observar a ornamentação desta espécie em nenhum dos espécimes estudados.

\section{Discussão:}

O gênero Bellerophon Montfort, 1808, conforme a classificação apresentada em KNIGHT et alii (1960), pertence à subfamília Bellerophontinae M'Coy, 1851. Essa, segundo a descrição por eles apresentada, pode ser caracterizada por possuir "aspecto de Nautilus" e por apresentar voltas, comumente, bem arredondadas; umbílicos estreitos ou ausentes e linhas de crescimento. O gênero em apreço, por sua vez, ainda de acordo com os autores supracitados, teria voltas bem arredondadas e, às vezes, uma crista mediana. Com base nas ilustrações por eles apresentadas, essa última feição é aqui considerada como uma selenizona.

A espécie ora estudada é incluída, em trabalhos anteriores, no gênero Bellerophon (vide sinonímia). Entretanto, os exemplares da mesma apresentam, nitidamente, caracteres que não permitem atribuí-la ao referido gênero. Ela não possui voltas amplamente arredondadas, nem a "crista periférica estreita" (Est. II, figs. 9a, 9b) da espécie-tipo, Bellerophon 
vasulites. Também não exibe feições da subfamília Bellerophontinae, como o aspecto de Nautilus, pois tem dois sulcos rasos, que delimitam uma ampla região mediana e umbílicos visíveis (Est. II, figs. 9a, 9b).

Apesar da espécie não apresentar pseudo-selenizona, a trilobação da concha, o lobo mediano amplo e a ausência de selenizona verdadeira permitem atribuí-la ao gênero Bucanella, tal como definido no presente estudo, e conseqüentemente à subfamília Bucanellinae.

Os exemplares examinados no presente estudo foram incluídos na espécie Bucanella quadrilobata (Salter, 1856), por apresentarem características como trilobação moderada, lobo mediano bastante amplo e arredondado, umbílicos muito pequenos e volta corporal moderadamente expandida.

B. quadrilobata apresenta afinidade com duas espécies devonianas registradas por CLARKE (1899) para o Estado do Pará: $\boldsymbol{B}$. (P.) ? salteri Clarke, 1899 e B. (P.) reissi Clarke, 1899. B. (P.) ? salteri assemelha-se à espécie paranaense por apresentar volta corporal ligeiramente trilobada e pouco expandida, sulcos rasos separando o lobo mediano dos laterais e umbílicos pequenos. Difere de $\boldsymbol{B}$. quadrilobata, no entanto, pelo contorno do lobo mediano estreito e dorsalmente achatado e pelo sinus em forma de "V". B. ( $\boldsymbol{P}$.) reissi apresenta, tal como a espécie paranaense, trilobação pouco marcada e lobo mediano convexo. Porém, possui umbílicos maiores e sinus em forma de "V", características que não ocorrem em B. quadrilobata.

\section{5 - CONSIDERAÇÕES FINAIS}

A revisão dos gastrópodes devonianos do Estado do Paraná, iniciada por KOTZIAN \& MARCHIORO (1997) e concluída no trabalho agora apresentado, permite fazer algumas considerações gerais acerca dessa malacofauna. 
A taxocenose dos gastrópodes que ocorrem nos estratos em questão é constituída pelos belerofontinas Bucanella laticarinata, $\boldsymbol{B}$. dereimsi, B. hapsideus, B. quadrilobata, Ptomatis moreirai e $\boldsymbol{P}$. paranaensis sp. nov.; pelo pleurotomariáceo Pleurotomaria (?) kayseri; pelo platiceratáceo Platyceras (Platyostoma) allardycei var. circularis e por um exemplar pateliforme com posição sistemática indeterminada. Assinalam-se, assim, oito espécies de gastrópodes na região.

A composição taxonômica da associação supracitada variou durante o período deposicional da Formação Ponta Grossa. No Membro Jaguariaíva, ocorrem as espécies $\boldsymbol{P}$. paranaensis e $\boldsymbol{B}$. quadrilobata; no Membro Tibagi, as espécies $\boldsymbol{P}$. (?) kayseri, $\boldsymbol{P}$. (P.) allardycei var. circularis e B. dereimsi e no Membro São Domingos, os bucanelíneos: $\boldsymbol{B}$. quadrilobata, B. dereimsi, B. hapsideus, B. laticarinata e também $\boldsymbol{P}$. paranaensis e $\boldsymbol{P}$. (P.) allardycei var. circularis (Quadro 2).

\begin{tabular}{|l|l|}
\hline \multicolumn{1}{|c|}{ Membro } & \multicolumn{1}{c|}{ Espécies } \\
\hline São Domingos & $\begin{array}{l}\text { B. quadrilobata, B. dereimsi, B. hapsideus, B. laticarinata, } P \text {. } \\
\text { paranaensis, } P \text {. (P.) allardycei var. circularis. }\end{array}$ \\
\hline Tibagi & P. (?) kayseri, $P$. $(P)$ allardycei var. circularis, B. dereimsi \\
\hline Jaguariaíva & P. paranaensis, B. quadrilobata. \\
\hline
\end{tabular}

Quadro 2. Associações presentes nos três membros da Formação Ponta Grossa.

Cabe salientar, que algumas dessas espécies já haviam sido assinaladas em tais unidades. P. moreirai, B. hapsideus e B. dereimsi foram registradas, por PETRI (1948), no Membro Jaguariaíva. CIGUEL (1989) citou para o Membro Tibagi a presença de Bucanella sp. Entretanto, os espécimes observados por esses autores bem como por LANGE \& PETRI (1967) não 
foram encontrados nas coleções paleontológicas por nós visitadas. Portanto, a distribuição estratigráfica apresentada neste trabalho baseia-se, principalmente, nos dados aqui coligidos.

Se os registros de PETRI (1948) e CIGUEL (1989) não forem levados em consideração, seria possível sugerir, de forma generalizada, que o gênero Ptomatis ocorre de forma mais expressiva no Membro Jaguariaíva (Inferior) e os gêneros Bucanella e Platyceras, no Membro São Domingos (Superior).

Quanto à distribuição geográfica, as espécies $\boldsymbol{P}$. paranaensis e $\boldsymbol{P}$. moreirai foram registradas, até o momento, somente no Brasil. Com exceção de $\boldsymbol{B}$. laticarinata, que ocorre no Siluriano Superior dos Estados Unidos (HARRISON \& HARRISON, 1970), as demais espécies ocorrem na Bolívia, Argentina, África do Sul e Uruguai. A distribuição das espécies estudadas demonstra, portanto, que a maioria delas está restrita à Província Malvinocáfrica (MELO, 1985). .

Como comentado na introdução do presente estudo e por KOTZIAN \& MARCHIORO (1997), a distribuição temporal das espécies está baseada na ocorrência das mesmas nos quatro afloramentos cuja datação é conhecida: Estrada de Ferro Jaguariaíva-Arapoti (Km 3,2 - 4,2); Tibagi, Curva I (= Bairro Baraúna I ou localidade A25) e Rio Caniú. As espécies de gastrópodes encontradas nos demais jazigos estudados, os quais não contam com estudos bioestratigráficos, poderiam sugerir que tais afloramentos sejam correlacionáveis ao Membro São Domingos (Superior); (Quadro 3). Contudo, a proposição de uma correlação estratigráfica desses jazigos com aqueles já datados, baseada nos gastrópodes, seria precipitada. Não só a distribuição temporal das espécies estudadas ainda é pouco conhecida como, a julgar pelos trabalhos de PETRI (1948) e LANGE \& PETRI (1967), poderia ser mais ampla. 


\begin{tabular}{|l|l|}
\hline \multicolumn{1}{|c|}{ AFLORAMENTO } & \multicolumn{1}{c|}{ ESPÉCIES } \\
\hline Curva I & B. quadrilobata, $P$. paranaensis, P. allardycei \\
\hline Tibagi & P. (?) kayseri, P. allardycei \\
\hline Vila Velha & B. laticarinata, P. paranaensis \\
\hline Vila Placidina (=Posto) & B. hapsideus \\
\hline Vendrami & B. hapsideus \\
\hline Metalúrgica Águia & B. laticarinata, exemplar pateliforme \\
\hline Rio Caniú & B. laticarinata, B. dereimsi, B. hapsideus, P. allardycei \\
\hline Jaguariaíva & B.quadrilobata, P. paranaensis \\
\hline
\end{tabular}

Quadro 3- Associações encontradas nos afloramentos estudados.

Quanto à classificação, a nível de categorias taxônomicas superiores, as características conquiliológicas dos belerofontinas examinados permitem apresentar algumas considerações sobre a sistemática dos Mollusca.

RUNNEGAR (1987) propôs incluir todos os gastrópodes da subordem Bellerophontina na classe Monoplacophora. Tal procedimento, segundo ele, seria justificado pela presença de cicatrizes musculares pares e simétricas, ainda que em número reduzido, em alguns belerofontinas. Isso poderia significar que a torsão, principal característica a definir os gastrópodes atuais, não ocorre nesse grupo. Contudo, em nenhum dos belerofontinas aqui estudados foram observadas quaisquer cicatrizes musculares, não sendo possível atribuí-los, com segurança, à classe Monoplacophora e contribuir para o esclarecimento da posição taxonômica desses moluscos.

Por outro lado, a presença de pseudo-selenizona, ao invés de selenizona s. s., verificada em todas as espécies de Bucanella analisadas, assim como nas espécies de Ptomatis do Devoniano paranaense (KOTZIAN \& MARCHIORO, 1997) poderia corroborar a proposta de RUNNEGAR (1987), pelas razões expostas a seguir. A fenda pleurotomariana, associada à selenizona $s$. $s$., é uma característica 
destinada a solucionar certos efeitos da torsão, como desviar a corrente exalante da região cefálica. A presença de pseudo-selenizona, ao invés de selenizona, nas formas aqui estudadas poderia indicar a ausência de fenda pleurotomarina s. s. nas espécies estudadas. Portanto, poderia indicar que a sinuosidade ou inflexão da abertura "anterior" dos belerofontinas da Formação Ponta Grossa não representa uma adaptação para afastar a corrente exalante da região cefálica. Nesse caso, a pseudo-selenizona e a inflexão da abertura anterior poderiam ser feições de monoplacóforos onde, em princípio, a alteração da rota ventilatória seria desnecessária, já que o grupo não teria sofrido torsão.

Mas, se os gêneros Ptomatis e Bucanella forem realmente atribuídos aos monoplacóforos, então os Bellerophontina, tal como hoje caracterizados, constituem um grupo artificial já que alguns de seus representantes, como Plectonotus, possuem selenizona s. s. (KNIGHT et alii, 1960). Neste caso, a subordem Bellerophontina precisa ser revisada.

\section{6 - AGRADECIMENTOS}

Os autores agradecem às seguintes pessoas e instituições: Dra. Dea Regina Bouret Campos (DNPM), Dra. Marlene T. Barcellos-Popp (UFPR) e Fernando A. Sedor ( $\mathrm{MHNCl}$ ), pela atenção dispensada durante nossa visita às instituições que representam e pelo empréstimo de material para estudo; Prof. Dr. José Willibaldo Thomé (Pontifícia Universidade Católica -PUC - Porto Alegre), pelas sugestões no capítulo "Sistemática"; Prof. Dr. Marcelo Simões (UNESP - Botucatu) e Prof. Dr. Mário Assine (UFPR), pela leitura crítica do texto; Prof. João Carlos Coimbra (UFRGS), por proporcionar a nossa participação em excursões à Formação Ponta Grossa; Rosemary Pereira Pedroso (UFRGS), pela elaboração de fotografias; Dr. Paulo E. Menegotto (UFSM), pelo auxílio em viagens; CNPq, pela concessão de uma Bolsa de Iniciação Científica. Nossos 
agradecimentos especiais à Prefeitura Municipal de Ponta Grossa, através de Élvio e Loraine Bosetti, que gentilmente nos receberam, acompanhandonos ao campo e proporcionando-nos excursões a vários afloramentos do Estado do Paraná.

\section{7 - REFERÊNCIAS BIBLIOGRÁFICAS}

ANDRADE, S. M. \& CAMARÇO, P. E. N. 1978. Mapeamento Geológico a leste das cidades de Iporá - Amorinópolis. NUCLEBRÁS/DRM, $30 \mathrm{p}$. Relatório Interno.

ANDRADE, S. M. \& CAMARÇO, P. E. N. 1980. Estratigrafia dos sedimentos devonianos do flanco nordeste da Bacia do Paraná. In: CONGRESSO BRASILEIRO DE GEOLOGIA, 31, Camboriú. Anais... Camboriú, SBG v. 5, p.2828-2836.

ANDRADE, S. M. \& CAMARÇO, P. E. N. 1982. Seqüências sedimentares pré-carboníferas dos flancos nordeste da Bacia do Paraná e sudoeste da Bacia do Parnaíba e suas possibilidades uraníferas. In: CONGRESSO BRASILEIRO DE GEOLOGIA, 32, Salvador. Anais... Salvador, SBG, v. 5, p. 2132-2144.

ASSINE, M. L. \& SOARES, P. C. 1989. Correlações nas seqüências mesopaleozóicas da Bacia do Paraná. Acta Geológica Leopoldensia, São Leopoldo, v. 12, n. 29, p. 39-48.

ASSINE, M. L.; SOARES, P. C. \& MILANI, E. J. 1994. Seqüências tectonosedimentares mesopaleozóicas da Bacia do Paraná, sul do Brasil.

Revista Brasileira de Geociências, São Paulo, v. 24, n. 2, p. 77-89

BOSETTI, E. P. 1989. Paleontologia dos Lingulida (Brachiopoda: Inarticulata) da Formação Ponta Grossa, Devoniano, Bacia do Paraná, Brasil. Porto Alegre: Curso de Pós-Graduação em Geociências. 113 p., 10 est., 15 figs. Dissertação (Mestrado em Geociências). Instituto de Geociências. Universidade Federal do Rio Grande do Sul.

BOUCOT, A. J. 1971. Malvinokaffric Devonian marine community distribution and implications for Gondwana. Anais da Academia Brasileira de Ciências, Rio de Janeiro, Supl. 43, p. 23-49.

BOUCOT, A. J. 1985. Late Silurian-Early Devonian biogeography, provincialism, evolution and extinction. Philosophical Transactions of the Royal Society of London, London, B. 309, p. 323-339.

BOUCOT, A. J.; ROHR, D. M.; DE FARIA, Á.; COLBATH, G. K. 1986. Plectonotus and Plectonotoides, new subgenus of Plectonotus (Bellerophontacea: Gastropoda) and their biogeographic significance. 
Neues Jarbuch für Geologie und Paläontologie Abhandlungen, Stuttgart. v. 173, n. 2: 167-180 p.

BRANISA, L. 1965. Los fósiles guías de Bolivia: I. Paleozoico. Boletim del Servíço Geológico de Bolívia, La Paz, n. 6, p. 1-282.

CASTELLARO, H. A. 1966. Faunas Devónicas: Guia Paleontologica Argentina, Consejo Nacional de Investigaciones Cientificas y Tecnicas, Buenos Aires, p. 37-119.

CIGUEL, J. H. G. 1989. Bioestratigrafia dos Tentaculoidea no flanco oriental da Bacia do Paraná e sua ocorrência na América do Sul (Ordoviciano-Devoniano). São Paulo. 237 p., v. 1, v.2. Dissertação (Mestrado em Geociências), Instituto de Geociências. Universidade de São Paulo.

CLARKE, J. M. 1899. Molluscos devonianos do Estado do Pará, Brazil. Archivos do Museu Nacional, Rio de Janeiro, v. 10, p. 49-174, pl. 3-8.

CLARKE, J. M. 1913. Fósseis devonianos do Paraná. Monografia do Serviço Geológico e Mineralógico do Brasil, Rio de Janeiro, v. 1, p. 1353, Est. I-XXVII.

DAEMON, R. F.; QUADROS, L. P. \& SILVA, L. C. da. 1967. Devonian palynology and bioestratigraphy of the Paraná Basin. In: BIGARELLA, J. L. (ed) Problems in Brazilian Devonian Geology. Boletim Paranaense de Geociências, Curitiba, v. 21/22, p. 99-132.

GLASER, J. 1969. A Formação Furnas no SW de Goiás. In: CONGRESSO BRASILEIRO DE GEOLOGIA, 23, Salvador. Anais... Salvador. SBG, p. 135-144.

GOULD, S. J. 1977. Ontogeny and Phylogeny, Cambridge: Belknap/Harvard, 501 p., il.

HARRISON W. B. \& HARRISON, L. K. 1970. A Maquoketa-like molluscan community in the Brassfield Formation (Early-Silurian) of Adams county, Ohio. Bulletin American Paleontology, v. 67, n. 287, p. 193-234, pl. 15.

KNIGHT, J. B. 1941. Paleozoic gastropod genotype. Geological Society of America, Special Papers, New York, v. 32, 510 p.

KNIGHT, J. B.; COX, L. R.; KEEN, A. M.; BATTEN, R. L.; YOCHELSON, E. L. \& ROBERTSON, R. 1960. Systematic descriptions. In: MOORE, R. C. (ed) Treatise on Invertebrate Paleontology. Part I, Mollusca 1. Geological Society of American, New York. p. 169-351.

KNOD, R. 1908. Devonische Faunen Boliviens. In: STEIMANN, G. (ed.) Beiträge zur Geologie und Paläontologie von Sudamerika, pt. 4. Neues Jahrbuch für Mineralogie Geologie Paläontologie, Stuttgard, Beil. band XXV, p. 493-600, Taf. XXI-XXXI.

KOTZIAN, C. B. \& MARCHIORO, A. 1991. Revisão sistemática dos gastrópodes (Mollusca) devonianos do Estado do Paraná (Bacia do Paraná, Brasil). In: CONGRESSO BRASILEIRO DE PALEONTOLOGIA, 22, São Paulo, Resumos... São Paulo, SBP, p. 10.

KOTZIAN, C. B. \& MARCHIORO, A. (1997). Gastrópodes (Mollusca) devonianos da Formação Ponta Grossa (Bacia do Paraná). Gêneros: 
Ptomatis Clarke, 1899, Pleurotomaria (?) Defrance, 1826 e Platyceras

Conrad, 1840. Ciência e Natura, Santa Maria, v. 19, p.77-117.

KOZLOWSKI, R. 1913. Fossiles dévoniens de l'état de Paraná. Annales de

Paléontologie, Paris, v. 8, n. 3/4, p. 1-20, fl. I-III.

LANGE, F. W. 1967. Bioestratigraphic subdivision and correlation of

Devonian in the Paraná Basin. In: BIGARELLA, J. L. (ed) Problems in

Brazilian Devonian Geology. Boletim Paranaense de Geociências,

Curitiba, v. 21/22, p. 63-68, est. 1-5, fig. 1-3.

LANGE, F. W. \& PETRI, S. 1967. The Devonian of the Paraná Basin. In:

BIGARELLA, J. J. (ed) Problems in Brazilian Devonian Geology. Boletim

Paranaense de Geociências, Curitiba, v. 21/22, p. 5-55, fig. 1-5.

MELO, J. H. G. de 1985. A Província Malvinocáfrica no Devoniano do

Brasil; estado atual dos conhecimentos. Rio de Janeiro: Curso de

Pós-Graduação em Geociências. v. 1, 800 p.; v. 2, 467 p.; v. 3, 182 figs.

Dissertação (Mestrado em Geociências). Instituto de Geociências.

Universidade Federal do Rio de Janeiro.

MELO, J. H.G. de 1988. The Malvinokaffric Realm in the Devonian of Brazil.

In: McMILLAN, N. J.; EMBRY, A. F. \& GLASS, D. J. (eds) Devonian of

the World. Canadian Society of Petroleum Geologists, Calgary, Memoir.

n. 14 , v. 1 , p. $669-703$.

MENDEZ-ALZOLA, K. 1934. Contribuición al conocimiento de la fauna devónica de Ricón de Alonso. Boletin del Instituto de Geologia y

Perforaciones del Uruguay, Montevidéu, v. 21, p. 21-55, Lám. III-IV.

MENDEZ-ALZOLA, K. 1938. Fósiles devónicos del Uruguay. Boletin del

Instituto Geológico del Uruguay, Montevidéu, v. 24, 115 p., 15 pls.

MOORE, R. C. 1960. Treatise on Invertebrate Paleontology. Part I,

Mollusca 1. Geological Society of America, University of Kansas Press, New York. $351 \mathrm{p}$.

ÖPIK, A. A. 1953. Lower Silurian fossils from the "Illaenus band" heathcote,

Victoria. Geological Survey of Victoria, Melbourne, v. 19, p. 17-21, pl. VI-VII.

PEEL, J. S. 1987. Gastropoda. In: BOARDMAN, R. S. Fossil Invertebrates, Blackwell, London, p. 304-329.

PETRI, S. 1948. Contribuição ao estudo do devoniano paranaense. Boletim do Departamento de Produção Mineral, Divisão de Geologia e Mineralogia, Rio de Janeiro, v.192, p. 1-125.

POPP, J. H. \& BARCELLOS-POPP, M. 1986. Análise Estratigráfica da Sequência Deposicional da Bacia do Paraná (Brasil). Revista Brasileira de Geociências, São Paulo, v.16, n. 2, p. 187-194.

POPP, M. T. B. 1985. Revisão dos trilobitas calmoniídeos e comunidades faunísticas da Formação Ponta Grossa, Devoniano no Estado do Paraná. Porto Alegre: Curso de Pós-Graduação em Geociências, 109 p., 6 est., bibliogr. Tese (Doutorado em Geociências) - Instituto de Geociências. Universidade Federal do Rio Grande do Sul. 
RAMOS, A. N. 1970. Aspectos páleo-estruturais da Bacia do Paraná e sua influência na sedimentação. Boletim Técnico da Petrobrás, Rio de Janeiro, v. 13, n. $3 / 4$, p. 85/93.

RAUP, D. M. \& STANLEY, S. M. 1971. Principles of Paleontology. Freeman, San Francisco. 383 p. il.

REED, F. R. C. 1904. Mollusca from the Bokkeveld Beds. Annals of the South African Museum, London, v. 4, p. 239-272, PI. XXX-XXXII

REED, F. R. C. 1925. Revision of the Fauna of Bokkeveld Belds. Annals of the South African Museum, Edinburgh, v. 22, p. 27-225, PI. IV-XI.

RICHTER, R. \& RICHTER, E. 1942. Die trilobiten der Weismes-Schichten am Hohen Venn, mit Bemerkungen über die Malvinocaffrische Provinz. Senckenbergiana, Frankfurt, v. 25, n. 1/3, p. 156-79.

RONCARATI, H. 1968. Geologia em semi-detalhe da região de Amorinópolis, Ivolândia e Cachoeira de Goiás (SW de Goiás). Ponta Grossa. PETROBRÁS. (inédito).

RUNNEGAR, B. 1987. Monoplacophora. In: BOARDMAN, R. S. Fossil Invertebrates, Blackwell, London: p. 297-304.

SALTER, J. W. 1856. Description of Paleozoic Mollusca from South Africa. Transactions of the Geological Society of London, Series 2, v. 7, p. 206-215, pls. 26-27

SAUL, J. M.; BOUCOT, A. J.; FINKS, R. M. 1963. Fauna of Accraian Series (Devonian of Ghana) including a revision of the gastropod Plectonotus. Journal of Palaentology, Tulsa, v. 37, p. 1042-1053.

SCHNEIDER, R. L.; MUHLMANN, H.; TOMMASI, E.; MEDEIROS, R. A.; DAEMON, R. F. \& NOGUEIRA, A. A. 1974. Revisão estratigráfica da Bacia do Paraná. In: CONGRESSO BRASILEIRO DE GEOLOGIA, 28, Porto Alegre Anais... Porto Alegre, SBG, v.1, p. 41-65, il.

SEILACHER, A. 1984. Constructional morphology of bivalves: evolutionary pathways in primary versus secondary soft-bottom dwellers. Palaeontology, London, v. 27, part. 2, p. 207-237.

ZALÁN, P. V.; WOLFF, S.; CONCEIÇÃO, J. C. J.; VIEIRA, I. S.; ASTOLFI, M. M. M.; APPI, V. T. \& ZANOTTO, O. A. 1987. A divisão tripartite do Siluriano da bacia do Paraná. Revista Brasileira de Geociências, São Paulo, v. 17, n. 3, p. 242-252.

ZALÁN, P. V.; WOLFF, S.; CONCEIÇÃO, J. C.; MARQUES, A; VIEIRA, I. S.; ASTOLFI, A. M.; APPI, V. T. \& ZANOTTO, O. A. 1990. Bacia do Paraná, In: RAJA-GABAGLIA, G. P. \& MILANI E. J. (Coord), Origem e Evolução de Bacias Sedimentares. Rio de Janeiro: PETROBRÁS, p. 135-168. 


\section{ESTAMPA I}

\section{Bucanella laticarinata Knod, 1908}

Fig. 1 - GPE-1T 1893 (afloramento Rio Caniú, Palmeira, PR). Molde composto de um exemplar não deformado. Fig. 1a. Vista posteroventral mostrando a maior largura do lobo mediano em relação à dos laterais e a ranhura posterior (seta). Escala $\cong 0,4 \mathrm{~cm}$. Fig. $1 \mathrm{~b}$. Vista lateral direita mostrando o umbílico e o sinus anterior em forma de "V" (seta). Escala $\cong 0,4 \mathrm{~cm}$.

Fig. 2 - GPE-1T 1891 (afloramento Rio Caniú, Palmeira, PR). Molde interno de um exemplar pouco compactado. Fig. 2a. Vista posterior mostrando o aspecto quadrilobado da espécie devido ao achatamento (seta) da periferia (pseudo-selenizona) do lobo mediano. Escala $\cong 0,2$ $\mathrm{cm}$. Fig. 2b. Vista lateral direita mostrando a nítida delimitação da pseudo-selenizona (seta pequena) e a abertura com formato de "V" (seta grande). Escala $\cong 0,3 \mathrm{~cm}$.

\section{Bucanella dereimsi Knod, 1908}

Fig. 3 - DGM-I 98 (Ponta Grossa, PR). Molde composto de um exemplar compactado dorsoventralmente mostrando a largura, aproximadamente igual, dos três lobos da concha (vista dorsal). Escala $\cong 0,6 \mathrm{~cm}$.

Fig. 4 - GPE-1T 1900 (afloramento Rio Caniú, Palmeira, PR). Amostra contendo vários moldes compostos de espécimes jovens, algo compactados lateralmente. Fig. 4a. Vista lateral de diversos exemplares mostrando os umbílicos pequenos, o lobo mediano nitidamente demarcado dos lobos laterais e a convexidade mais acentuada destes em relação ao mediano. Escala $\cong 0,4 \mathrm{~cm}$. Fig. $4 \mathrm{~b}$. Vista lateral de dois exemplares exibindo a alteração da ornamentação dos lobos laterais. Nas primeiras voltas a escultura é radial (seta pequena), tornando-se concêntrica à medida que a concha aumenta de tamanho (seta grande). Escala $\cong 0,2 \mathrm{~cm}$.

Fig. 5 - DGM-I 101 (Ponta Grossa, PR). Molde composto de um exemplar compactado dorsoventralmente, com a ornamentação radial nitidamente marcada nos três lobos da concha (vista dorsal). A seta indica a marca deixada por uma antiga margem do sinus anterior, em forma de "U". Escala $\cong 0,5 \mathrm{~cm}$.

Fig. 6 - DGM-I 100 (Ponta Grossa, PR). Molde composto de um exemplar compactado dorsoventralmente mostrando as linhas radiais do lobo mediano (vista dorsal). Escala $\cong 0,7 \mathrm{~cm}$. 


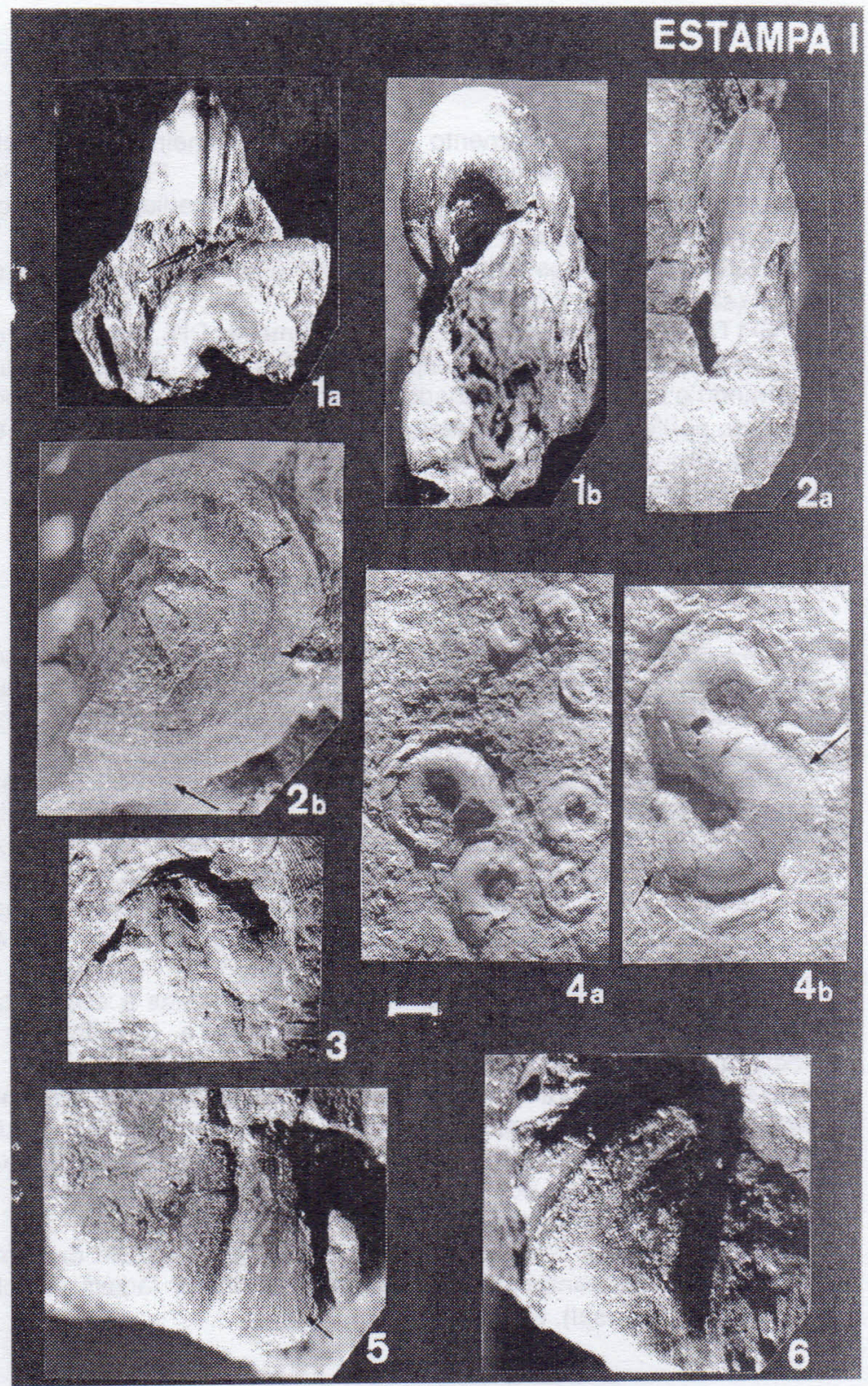

182 Rev. Ciência e Natura. Santa Maria, 20: 143 - 185 , 1998 


\section{ESTAMPA II}

Bucanella hapsideus (Clarke, 1913) comb. nov.

Fig. 1 - Paralectótipo DGM-I 103 (Ponta Grossa, PR). Molde composto de um exemplar compactado lateralmente, mostrando as estrias radiais (seta) que delimitam a pseudo-selenizona da área restante do lobo mediano (vista lateral direita). Escala $\cong 0,5 \mathrm{~cm}$.

\section{Plectonotus derbyi Clarke, 1989}

Fig. 2 - DGM-I 2786 (Estado do Pará, Brasil). Molde composto de um exemplar compactado dorsalmente. A seta indica a selenizona, nitidamente escavada sobre o lobo mediano (vista dorsal). Escala $\cong$ $0,4 \mathrm{~cm}$.

Bucanella hapsideus (Clarke, 1913) comb. nov.

Fig. 3 - GPE-1T 1906 (afloramento Vendrami, Ponta Grossa, PR). Molde composto de um exemplar compactado dorsoventralmente, bastante recoberto pela rocha matriz, mostrando a sinuosidade da ornamentação do lobo mediano, correspondente às antigas margens do sinus anterior (seta grande); as linhas espirais que delimitam a pseudo-selenizona (seta pequena) do restante do lobo mediano e as linhas espirais da periferia do lobo mediano (seta pontilhada) (vista dorsal). Escala $\cong 0,2 \mathrm{~cm}$.

Fig. 4 - Paralectótipo DGM-I 105 (Ponta Grossa, PR). Molde composto de um exemplar algo compactado lateralmente mostrando a profunda inflexão do sinus anterior (seta) e a convexidade pronunciada dos lobos laterais (vista lateral direita). Escala $\cong 0,5 \mathrm{~cm}$.

Fig. 5 - Lectótipo DGM-I 104 (Ponta Grossa, PR). Molde composto de um exemplar não deformado, mostrando a proeminência do lobo mediano e a forte convexidade dos laterais (vista lateral direita). Escala $\cong 0,4$ $\mathrm{cm}$.

Fig. 6 - GPE-1T 1905 (afloramento Vila Placidina, Ponta Grossa, PR). Molde composto de um exemplar bastante compactado lateralmente, mostrando a ornamentação comarginal e as estrias radiais (seta) que delimitam a pseudo-selenizona (vista lateral direita). Escala $\cong 0,4 \mathrm{~cm}$.

Fig. 7 - GPE-1T 1902 (afloramento Rio Caniú, Palmeira, PR). Molde composto de um exemplar pouco deformado mostrando a ornamentação comarginal e as estrias radiais. A seta indica uma antiga margem do sinus anterior em forma de "U". Escala $\cong 0,4 \mathrm{~cm}$.

Fig. 8 - Paralectótipo DGM-I 102 (Ponta Grossa, PR). Molde composto de um exemplar não compactado, mostrando a profunda inflexão do sinus anterior (seta), a convexidade pronunciada dos lobos laterais e a proeminência do lobo mediano (vista lateral direita). Escala $\cong 0,4 \mathrm{~cm}$. 
Bucanella quadrilobata (Salter, 1856) comb. nov.

Fig. 9 - GPE-1T 1908 (afloramento Curva I, Ponta Grossa, PR). Contramolde de um exemplar não deformado. Fig. 9a. Vista lateral direita mostrando o umbílico pequeno e circular. Escala $\cong 0,3 \mathrm{~cm}$. Fig. $9 \mathrm{~b}$. Vista anterior mostrando a trilobação da concha e a "ausência" de pseudo-selenizona no lobo mediano. A seta indica a inflexão do sinus anterior, mal preservado no espécime ilustrado. Escala $\cong 0,3 \mathrm{~cm}$. 


\section{ESTAMPA II}
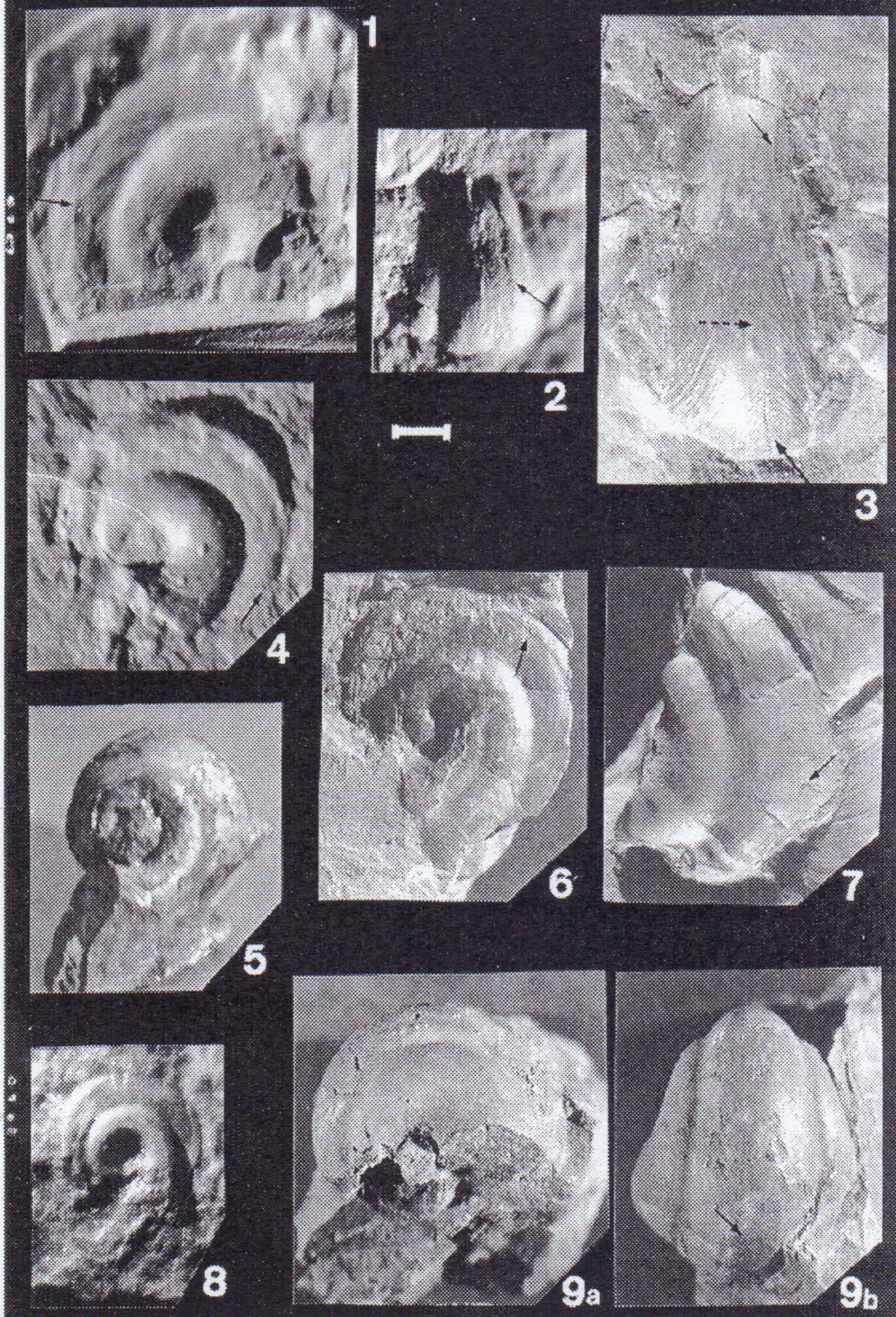
186 Rev. Ciência e Natura, Santa Maria, 20: 143 - 185 . 1998 